\title{
Testing a student generated hypothesis using student data
}

\author{
Herle M. McGowan \\ North Carolina State University, Raleigh, USA. \\ e-mail: herle_mcgowan@ncsu.edu \\ Joel Vaughan \\ University of Michigan, Ann Arbor, USA. \\ e-mail: rsnation@umich.edu
}

\begin{abstract}
We describe an activity that allows students to experience the full process of a statistical investigation, from generating the research question, to collecting data and testing a hypothesis. Implementation of the activity is described both with and without use of clickers, handheld remotes that allow instant data collection.
\end{abstract}

Keywords: $\quad$ Teaching; Statistical thinking; Hypothesis testing; Clickers.

\section{Introduction}

This paper discusses an activity about hypothesis testing for a population proportion that uses student data to answer a research question generated by the students. This activity meets recommendations from the Guidelines for Assessment and Instruction in Statistics Education (GAISE) reports, for both $\mathrm{K}-12$ and college level statistics, which were endorsed as bestpractice guidelines by the American Statistical Association (ASA). For example, the activity follows recommendations made in the college report to use active learning and to use real data to engage students (ASA 2005a). It also provides students a chance to run through the full process of statistical problem solving, including each of the four components of the 'Framework Model' presented in the GAISE $\mathrm{K}-12$ report (ASA 2005b). These four components are: formulate a research question, collect data, analyse data, and interpret the results. The data used in this activity are not only "real;" they are about and of interest to the students since they determine the research question and which data should be collected. While this activity was developed for use in an introductory statistic course for college undergraduates, it could easily be included in any classroom where hypothesis testing is taught. In the form presented here, the activity makes use of both the large-sample $z$ test and the small-sample binomial test; however, it could be modified to involve just one of these tests. Implementation of the activity is described both with and without the use of "clickers," a technology that is becoming increasingly common in classrooms.

\section{About clickers}

Clickers go by several names in the literature: personal, student, audience, or classroom response systems are some of the most common. They have been used predominately in college courses, but have more recently been used in elementary and secondary education as well (e.g. Chen et al. 2005; Conoley et al. 2006). Penuel et al. (2007) conducted a survey of nearly 500 elementary and high school instructors who used clickers and found that implementation of the technology in this group was very similar to implementation at the college level. One of the most common ways to use clickers is with 'peer instruction' (Mazur 1997), in which students have the chance to discuss a question with their classmates. Clickers have also been used to explore students' prior knowledge of a topic (Beatty 2004), or to verify that assigned reading was completed (Beekes 2006). Proponents of clicker use suggest that content questions should focus on conceptual understanding, rather than memorization of facts or procedures, and several guides for writing good conceptual questions exist in the literature (Beatty 2004; Beatty et al. 2006; Caldwell 2007; Duncan 2005; Zhu 2007). 
Not all uses of clickers involve questions pertaining to course content. Another way to incorporate the technology that is particularly well suited to a statistics class is as a tool to gather data for analysis or case study (Brickman 2006; Cleary 2008; Haidet et al. 2002; Herreid 2006). In the activity described here, clickers are used to collect student data in real time.

\section{The activity}

The content of the activity deals with hypothesis testing for a population proportion $p$. The population for the activity is the students' school, with the class being considered a representative sample of all students in the school. This assumption is itself an interesting point for discussion - thinking about in what ways the students in the class might or might not be a good representation of the entire student body - but this is not the focus of the activity presented here.

The first step in the activity is for students to decide on a research question of interest to them, according to the general form:

"Do a majority of students in this school $<<$ blank $>>$ ?"

Examples from previous semesters include: "Did a majority of students in this school attend the homecoming game?" or "Are a majority of students in this school the eldest sibling in their family?" Students could focus on one question as an entire class, or several questions of this form could be identified and answered by different groups. This is one benefit of using clickers for this activity: data for several variables can be gathered in very little time. Implementation without clickers may take longer.

After selecting a research question, students use a handout (see the Appendix at the end of this article) to walk through the steps of a hypothesis test, including:

1. defining the parameter and stating the hypotheses;

2. checking if the conditions are met for using the large sample $z$ test (one standard being $n p \geq$ 10 and $n(1-p) \geq 10)$ and then calculating the appropriate test statistic;

3. finding the corresponding $p$-value;

4. stating the decision ('Reject $\mathrm{H}_{0}$ ' or 'Fail to reject $\left.\mathrm{H}_{0}{ }^{\prime}\right)$; and

5. stating the real-world conclusion in the context of the problem.

Data collection occurs after students define the appropriate hypotheses. The instructor poses a question of the form: "Do you $<<$ blank $>>$ ?" to students. With clickers, a few seconds is given for students to respond "yes" or "no," and then the frequency of each response is displayed to the class. However, if clickers are not used, data could be collected through a simple paper survey, with responses counted relatively quickly by the instructor. A show of hands could also be used, but seeing how their peers respond could influence student answers. Students record the total number of responses, as well as the number and corresponding proportion of "yes" responses, before continuing with the remaining steps of the hypothesis test. Note that the handout concludes by asking students to consider a different hypothesis test in which the large sample conditions will not be met, in order to help them understand when it is appropriate to use a binomial test rather than the Normal approximation.

All of the clicker systems we are familiar with allow students to select from at least four answer choices; some systems allow for more choices, or even allow students to rank-order their answers. It is easy then to customize this activity to handle a variety of other hypothesis testing scenarios in which categorical data are collected (e.g. testing the independence of hair colour and eye colour using a chi-squared test).

For those with clicker systems that can accept numeric input, still other hypothesis tests may be conducted. For example, the class could test if the average number of hours spent studying per night is greater than 2 hours, or test if there is a difference in the average number of hours spent studying by male and female students. The student responses can be saved (anonymously, as before) in a spreadsheet and then emailed to students for analysis. This would require additional computing resources, but would save the time required for data entry from paper-and-pencil surveys.

\section{Conclusion}

This activity is a simple way for students to experience the process of using data - about themselves - to answer a research question generated by themselves. In this sense, it meets two of the GAISE recommendations: (1) foster active learning and (2) use real data. This activity also includes all four components of the GAISE 'Framework Model': formulating a research question (the first step of the activity), collecting data (with or without clickers), analyzing data (with a $z$ test or a binomial test), and 
finally interpreting the results (the final step of the hypothesis test). Additionally, this activity provides a novel use of clickers for statistics: collecting data in real time. It could also be implemented without clickers, using paper surveys or a show of hands; however, the technology allows the data to be collected instantly, without the need for data entry. Use of clickers also ensures the students that their response will be anonymous, a guarantee they may not get from other methods of data collection. In classrooms where clickers are already being used, incorporating this activity can be a fun way to get more out of this technology. In any classroom, this activity can be an interesting application of hypothesis testing.

\section{References}

ASA. (2005a). Guidelines for assessment and instruction in statistics education (GAISE) college report. http://www.amstat.org/Education/ gaise/ (accessed 16 February 2010).

ASA. (2005b). Guidelines for assessment and instruction in statistics education (GAISE): A pre-K-12 curricular framework. http:// www.amstat.org/Education/gaise/ (accessed 16 February 2010).

Beatty, I.D. (2004). Transforming student learning with classroom communication systems. Educause Center for Applied Research, Research Bulletin, February 3, Issue 3, http:// arxiv.org/ftp/physics/papers/0508/ 0508129.pdf (accessed 9 July 2010).

Beatty, I.D., Gerace, W.J., Leonard, W.J., and Dufresne, R.J. (2006). Designing effective questions for classroom response system technology. American Journal of Physics, 74(1), 31-39.

Beekes, W. (2006). The "Millionaire" method for encouraging participation. Active Learning in Higher Education, 7(1), 25-36.

Brickman, P. (2006). The case of the Druid Dracula: A directed "clicker" case study on DNA fingerprinting. Journal of College Science Teaching, 36(2), 48-53.
Caldwell, J.E. (2007). Clickers in the large classroom: Current research and best-practice tips. CBE Life Sciences Education, 6(1), 9-20.

Chen, Y.F., Liu, C.C., Yu, M.H., Chang, S.B., Lu, Y.C. and Chan, T.W. (2005). Elementary science classroom learning with wireless response devices implementing active and experimental learning. Proceedings of the Third IEEE International Workshop on Wireless and Mobile Technologies in Education, 96-103.

Cleary, A.M. (2008). Using wireless response systems to replicate behavioral research findings in the classroom. Teaching of Psychology, 35(1), 42-44.

Conoley, J., Moore, G., Croom, B. and Flowers, J. (2006). A toy or a teaching tool? The use of audience-response systems in the classroom. Journal of the Association for Career and Technical Education, 81(7), 46-49.

Duncan, D. (2005). Clickers in the Classroom: How to Enhance Science Teaching Using Classroom Response Systems. San Francisco: Pearson.

Haidet, P., Hunt, D. and Coverdale, J. (2002). Learning by doing: Teaching critical appraisal of randomized trials by performing an in-class randomized trial. Academic Medicine, 77(11), 1161-1162.

Herreid, C.F. (2006). "Clicker" cases: Introducing case study teaching into large classrooms. Journal of College Science Teaching, 36(2), 43-47.

Mazur, E. (1997). Peer Instruction: A User's Manual. Upper Saddle River, NJ: Prentice Hall.

Penuel, W.R., Boscardin, C.K., Masyn, K. and Crawford, V.M. (2007). Teaching with student response systems in elementary and secondary education settings: A survey study. Educational Technology Research and Development, 55(4), 315-346.

Zhu, E. (2007). Teaching with clickers. Center for Research on Learning and Teaching (CRLT) Occasional Papers, No. 22. http://ic.ucsc. edu/technologies/clickers/Zhu_Teaching_w_ Clickers_michigan.pdf (accessed 9 July 2010). 


\section{Appendix}

\section{Student activity sheet}

\section{Conducting a test on a proportion}

In this project, we are going to investigate using the sample proportion to test a theory about the value of the population proportion. For the purpose of this activity, we are going to assume that this class is a representative sample of the $\langle<$ school name $>>$ student body. Follow the steps below to practice using this test.

1. Determine a question to investigate by filling in the following question.

"Do a majority of students in this school ?"

Based on your question, write down the appropriate null and alternative hypotheses:

$H_{0}$ :

$H_{A}$ :

where

(symbol) represents: (verbal description of parameter)

2. Once the question has been determined, the instructor will pose the question to the class. Record the results below.

\begin{tabular}{|l|l|}
\hline Number of students responding: & \\
\hline Number of student who responded "yes": & \\
\hline $\begin{array}{l}\text { Sample proportion of student who responded "yes" (symbol and } \\
\text { value): }\end{array}$ & \\
\hline
\end{tabular}

3. This test is often simplified by using a Normal approximation for the binomial. Provide the checks necessary to see if this approximation may be made:

4. Now, calculate the appropriate test statistic. (Ask yourself if you are making an approximation or doing an exact binomial test.) What is the (approximate) distribution of the test statistic under the null hypothesis?

5. Use your test statistic in part (4) to estimate the corresponding $p$-value.

6. What is your decision at the $5 \%$ level? 'Reject $H_{0}$ ' or 'Fail to reject $H_{0}$ ' (circle one). Also write out your real world conclusion in the context of the problem.

7. Suppose instead of testing to see if there was a majority, you were testing to see if at least $90 \%$ of the students at <<school name $>$ have ever owned a pet. Would you be able to use the Normal approximation? Why or why not? 